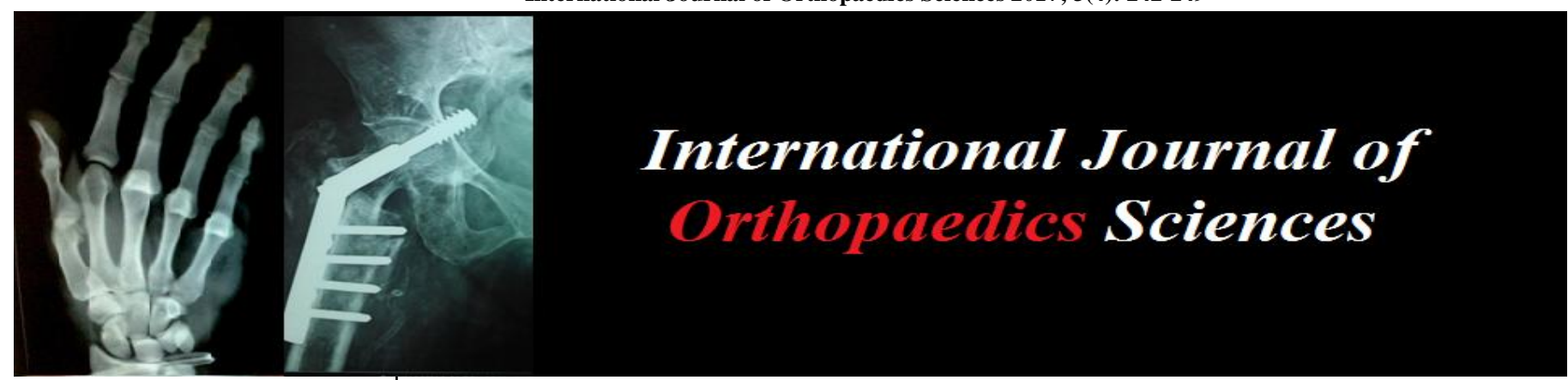

ISSN: $2395-1958$

IJOS 2017; 3(4): 242-249

(C) 2017 IJOS

www.orthopaper.com

Received: 11-08-2017

Accepted: 13-09-2017

Dr. Rahul Ramesh Kumar

Agrawal

Arthroplasty Fellow, Sunshine

Hospital, Secunderabad,

Telangana, India

Dr. Tushar Ranjan Dalei

Arthroplasty Fellow, Sunshine

Hospital, Secunderabad,

Telangana, India

Dr. AV Gurava Reddy

Head of Arthroplasty and

Managing Director, Sunshine

Hospital, Secunderabad,

Telangana, India
Correspondence

Dr. Rahul Ramesh Kumar Agrawal

Arthroplasty Fellow, Sunshine

Hospital, Secunderabad,

Telangana, India

\section{Computer tomography 3D reconstruction based study of knee anthropometry of Indian population: Comparison with other ethnic groups and current TKA implants}

\author{
Dr. Rahul Ramesh Kumar Agrawal, Dr. Tushar Ranjan Dalei and Dr. AV \\ Gurava Reddy
}

DOI: https://doi.org/10.22271/ortho.2017.v3.i4d.34

Abstract

Introduction: Most of the implants used for total knee arthroplasty in Asian patients have been produced based on anthropometry of Western people. Anthropometric studies have shown that there are significant variations in knee morphology between the Asian and Western population. Data of Indian knee morphometry of healthy and non osteoarthritic knee was lacking. Objective of this study was to study the knee anthropometry of Indian population and its comparison with other ethnic groups and current TKA Implants.

Materials and Methods: 60 patients, 29 female and 31 male with peri-articlar knee injuries from the period of June 2016 to November 2016 were studied. 3D reconstruction of normal knee of the patients undergoing CT scan for injured knee was done. Measurement of the mediolateral width, anteroposterior width and aspect ratio of distal femur and proximal tibia was done. Data was compared with other ethnic groups and currently available and commonly used knee systems.

Results: Indian females were found to have significantly ( $p>0.01)$ smaller dimensions of femur and tibia than Indian males and both had smaller aspect ratios than the Western population. Also study suggests that there is a morphological mismatch between commonly used implants and Indian knees.

Conclusion: Our study suggests that why Western implant mismatches when implanted in Indian patients. Also this study provides definite rationale for designing total knee prosthesis, especially a gender-specific design suitable for the Indian population.

Keywords: Total knee arthroplasty, TKA, anthropometry, knee morphology, aspect ratio

\section{Introduction}

Most of the implants used for total knee arthroplasty (TKA) in Asian patients have been produced based on anthropometry of western people. Since anatomic features and life styles are different between western and eastern people, there would be ethnic differences in terms of conformity of implants to the patient's anatomy and clinical results after TKA ${ }^{[1]}$. Being shortage of data on the morphometry of distal femur and proximal tibia in the Indian population, implants designed for knees of the western population are being used without modifications for the ethnic group ${ }^{[2]}$. Anthropometric studies have shown that there are striking variations in knee morphology between the Asian and western population ${ }^{[3]}$.

In TKA, maximal implant coverage on the bone surface minimizes the stress applied to the bone-implant interface ${ }^{[4,5]}$. A good shape of the knee prosthesis which matches the resected surface of knee has been reported as a factor for long-term survivorship in TKA ${ }^{[6]}$.

Research on implant mismatching carried out in various Asian countries has led to the conclusion that the Asian-Pacific population should have special designs of TKA implants ${ }^{[7,8,9]}$. Data of Indian knee morphometry of healthy and non-osteoarthritic knee was lacking [10]. Objective of this study was to study the knee anthropometry of Indian population and its comparison with other ethnic groups and current TKA Implants. This study representative of the Indian population can be used to manufacture prosthetic inventories suitable for most of the Asian-Pacific population having smaller knee anthropometry. 


\section{Materials and Methods}

\subsection{Subjects}

We studied 60 patients, 29 female and 31 male who came to the hospital with peri-articlar knee injuries from the period of June 2016 to November 2016. 3D reconstruction of normal knee of the patients undergoing CT scan for injured knee was done. Patients with bilateral knee injuries and knee with osteoarthritis or inflammatory arthritis were excluded from the study.
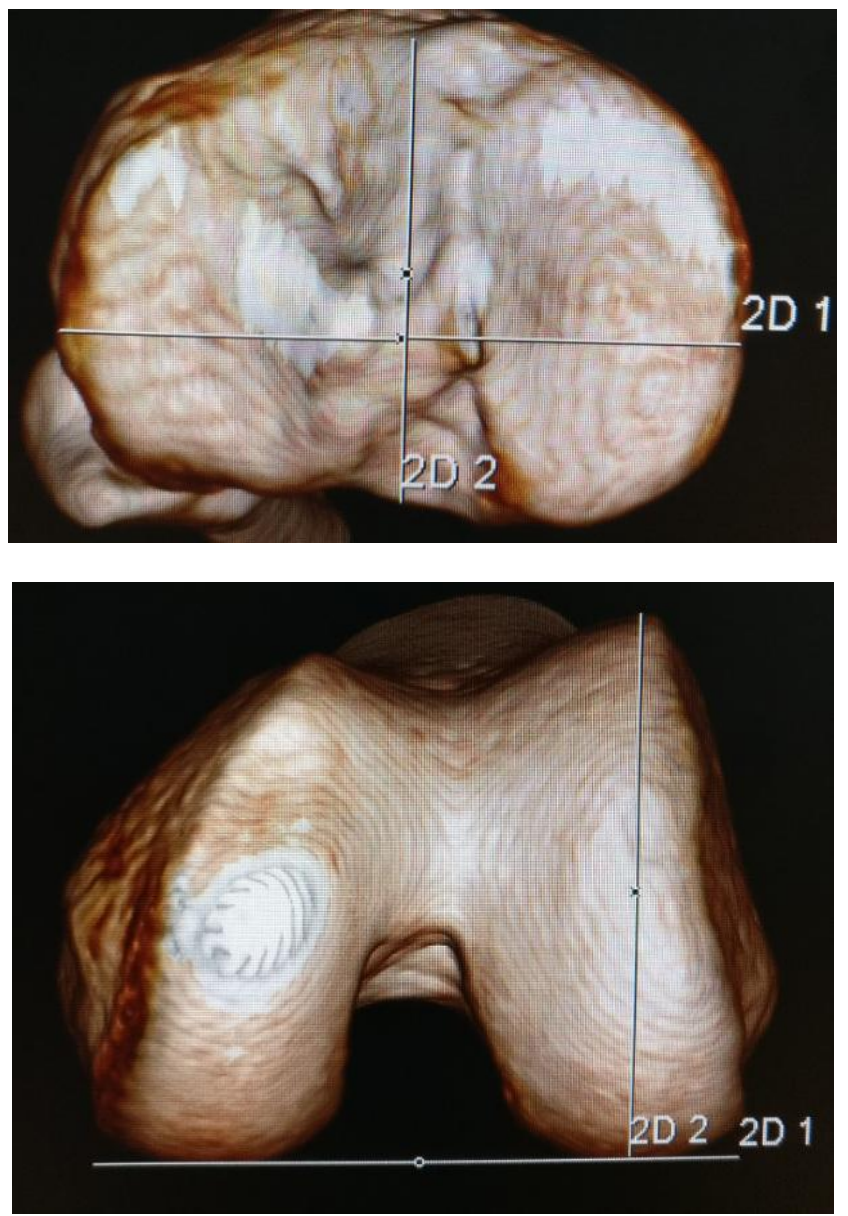

Fig 1: 3D reconstructed image of proximal tibia and distal femur

\subsection{CT scan technique}

All CT scans of knee were performed on 64 sliced helical CT scan system (Seimans Healthineers). During the scan, the subject was lying supine with his or her knee in a relaxed and extended position. The scanning procedure was performed to acquire $0.625 \mathrm{~mm} \mathrm{CT}$ slices (resolution, $512 \times 512$ pixels) with a field of view of $360 \times 360 \mathrm{~mm}$ around knee joint. The raw data obtained from the scans was first copied in DICOM file format. 3D reconstruction of raw data of the normal side was done.

\subsection{Femoral Morphology}

The medio-lateral (fML) and antero-posterior (fAP) size of the femur was measured using a viewing plane set perpendicular to the femoral long axis. The femur was rotated about its long axis so as to make the posterior condylar tangent line horizontal. The fML and fAP dimensions of the femur were then measured. In addition, the femoral aspect ratio (fML/fAP) was also calculated ${ }^{[11] .}$

\subsection{Tibial Morphology}

The tibial long axis was passing through the middle of the tibial spines and oriented parallel to the posterior wall of the tibial shaft in the sagittal plane. In the coronal plane, it was angled equally with respect to the medial and lateral edges of the tibial shaft ${ }^{[11]}$

The tibia was rotated about its long axis. The tML dimension was taken as the longest medio-lateral length of the proximal tibial surface. The tAP dimension was taken as perpendicular to tML and passing through the midpoint of the tibial intercondylar eminence ${ }^{[7,12]}$. Subsequently, the tibial aspect ratio (tML/tAP) was calculated.

\subsection{Comparison with different ethnic groups and knee systems}

Data obtained from this study was compared to available data of Americans, Chinese, Japanese and Korean knees. Also comparison of data with five commonly used knee systems at our center which included PFC Sigma Knee System (DePuy), NexGen LPS Flex Mobile Knee System (Zimmer) and Scorpio NRG Knee System (Stryker), Freedom (MAXX) and Buechal Pappas, was done.

\subsection{Statistical Analysis}

Comparative statistical analyses between genders were made using the paired t-test for parametric continuous data. Linear regression analysis was performed to determine correlations of simulated bones and size-matched components among 5 total knee prosthetic systems. A $p$ value of $<0.05$ was considered as statistically significant. All analysis was performed using SPSS 20.0 software.

\section{Results}

60 knees were included in the study, in which 29 were female and 31 were male. Mean age of male patients was $39 \pm 10.5 \mathrm{yrs}$ and of female patients was $38 \pm 9.9$ yrs (Table 1$)$.

Table 1: Subject Demographics

\begin{tabular}{|c|c|c|c|}
\hline & Total & Female & Male \\
\hline Number & 60 & 29 & 31 \\
\hline Age: mean \pm SD & $38 \pm 9.9(20-$ & $37 \pm 9.1(20-$ & $39 \pm 10.5(22-$ \\
(Range) & $54)$ & $52)$ & $54)$ \\
\hline
\end{tabular}

\subsection{Morphology of Indian Knee}

Mean fML was found to be $72.0 \pm 5.7 \mathrm{~mm}$ in whole population under study while mean fAP was $61.1 \pm 4.0 \mathrm{~mm}$. Average femoral aspect ratio was $1.18 \pm 0.6$. Males had larger values of fML and fAP as compared to females $(\mathrm{p}<0.001)$. A positive correlation was observed between fAP and fML for both males and females. In case of the femoral aspect ratio, statistically significant difference was found between males and females $(p<0.001)$. Femoral measurements for the study population have been compared across genders in Table 2 .

The average tML length was $70.4 \pm 5.8 \mathrm{~mm}$ and average tAP length was $46.1 \pm 4.0 \mathrm{~mm}$. The average tibial aspect ratio was $1.52 \pm 0.08$. Males had larger values of tML and tAP as compared to females $(\mathrm{p}<0.001)$. A positive correlation was observed between tAP and tML for both the genders. In case of the tibial aspect ratio, no statistically significant difference was found between males and females $(p=0.78)$. Tibial measurements for the study population have been compared across genders in Table 2.

\subsection{Comparison across other ethnicities}

To compare the Indian knees morphologically with other ethnic groups, the anthropometric measurements of knees of various ethnicities were retrieved from literature. The data of the distal femur of study population was compared with that 
of American, Chinese, Japanese and Korean population (Table 3). Also the data of the proximal tibia of the study population was compared to that of American, Chinese, Japanese and Korean population as shown (Table 4).

Table 2: Distal femoral and proximal tibial morphology.

\begin{tabular}{|c|c|c|c|c|}
\hline & Total Mean \pm SD (Range) & Female Mean \pm SD (Range) & Male Mean \pm SD (Range) & P value \\
\hline fML & $72.0 \pm 5.7(60.1-81.3)$ & $67.4 \pm 3.7(60.1-74.2)$ & $76.4 \pm 3.2(69.9-81.3)$ & $<0.001$ \\
\hline fAP & $61.1 \pm 4.0(51.9-68.5)$ & $59.4 \pm 4.1(51.9-68.5)$ & $62.7 \pm 3.2(56.8-68.3)$ & $<0.001$ \\
\hline fML/fAP & $1.18 \pm 0.6(1.03-1.29)$ & $1.13 \pm 0.5(1.03-1.28)$ & $1.21 \pm 0.4(1.14-1.29)$ & $<0.001$ \\
\hline tML & $70.4 \pm 5.8(60.7-84.2)$ & $65.8 \pm 3.9(60.7-74.3)$ & $74.7 \pm 3.6(69.9-84.2)$ & $<0.001$ \\
\hline tAP & $46.1 \pm 4.0(38.5-53.1)$ & $43.1 \pm 3.0(38.5-50.4)$ & $48.9 \pm 2.6(42.0-53.1)$ & $<0.001$ \\
\hline tML/tAP & $1.52 \pm 0.08(1.40-1.79)$ & $1.52 \pm 0.08(1.42-1.79)$ & $1.52 \pm 0.08(1.40-1.78)$ & 0.78 \\
\hline
\end{tabular}

Table 3: Distal femoral morphology of various ethnic groups.

\begin{tabular}{|c|c|c|c|}
\hline & fML & fAP & fML/fAP \\
\hline $\begin{array}{c}\text { Indians } \\
\text { (Our Study) }\end{array}$ & $\begin{array}{c}72.0 \pm 5.7(\mathrm{C}) \\
67.4 \pm 3.7(\mathrm{~F}) \\
76.4 \pm 3.2(\mathrm{M})\end{array}$ & $\begin{array}{c}61.1 \pm 4.0(\mathrm{C}) \\
59.4 \pm 4.1(\mathrm{~F}) \\
62.7 \pm 3.2(\mathrm{M})\end{array}$ & $\begin{array}{l}1.18 \pm 0.6(\mathrm{C}) \\
1.13 \pm 0.5(\mathrm{~F}) \\
1.21 \pm 0.4(\mathrm{M})\end{array}$ \\
\hline $\begin{array}{l}\text { Americans } \\
\text { Berger et al. }{ }^{[13]} \\
\text { Griffin et al. }{ }^{[14]}\end{array}$ & $\begin{array}{c}75.4 \pm 2.3(\mathrm{~F}) \\
85.6 \pm 5.1(\mathrm{M}) \\
78.0 \pm 6.7(\mathrm{C}) \\
74.1 \pm 4.6(\mathrm{~F}) \\
84.1 \pm 4.4(\mathrm{M})\end{array}$ & $\begin{array}{c}60.2 \pm 2.0(\mathrm{~F}) \\
68.1 \pm 4.6(\mathrm{M})\end{array}$ & \\
\hline Chinese Cheng et al. ${ }^{[6]}$ & $\begin{array}{c}71.0 \pm 3.0(\mathrm{C}) \\
66.8 \pm 3.1(\mathrm{~F}) \\
74.4 \pm 2.9(\mathrm{M})\end{array}$ & $\begin{array}{c}64.1 \pm 2.7(\mathrm{C}) \\
61.0 \pm 2.7(\mathrm{~F}) \\
66.6 \pm 2.4(\mathrm{M})\end{array}$ & $\begin{array}{c}1.11 \pm 0.03(\mathrm{C}) \\
1.09 \pm 0.04(\mathrm{~F}) \\
1.12 \pm 0.03(\mathrm{M})\end{array}$ \\
\hline Japanese Urabe et al. ${ }^{[8]}$ & $70.6 \pm 4.5(\mathrm{C})$ & & \\
\hline Koreans Lee et al. ${ }^{[17]}$ & $75(\mathrm{C})$ & & \\
\hline
\end{tabular}

(C-Combined males \& females, F- female, M- male)

Table 4: Proximal tibial morphology of various ethnic groups.

\begin{tabular}{|c|c|c|c|}
\hline & tML & tAP & tML/tAP \\
\hline \multirow{3}{*}{$\begin{array}{c}\text { Indians } \\
\text { (Our Study) }\end{array}$} & $70.4 \pm 5.8(\mathrm{C})$ & $46.1 \pm 4.0(\mathrm{C})$ & $1.52 \pm 0.08(\mathrm{C})$ \\
\hline & $65.8 \pm 3.9(\mathrm{~F})$ & $43.1 \pm 3.0(\mathrm{~F})$ & $1.52 \pm 0.08(\mathrm{~F})$ \\
\hline & $74.7 \pm 3.6(\mathrm{M})$ & $48.9 \pm 2.6(\mathrm{M})$ & $1.52 \pm 0.08(\mathrm{M})$ \\
\hline Americans & $70.1 \pm 2.8(\mathrm{~F})$ & $42.1 \pm 1.7(\mathrm{~F})$ & \\
\hline Mensch et al. ${ }^{[15]}$ & $80.3 \pm 3.7(\mathrm{M})$ & $48.9 \pm 2.3(\mathrm{M})$ & \\
\hline \multirow{3}{*}{$\begin{array}{c}\text { Chinese } \\
\text { Cheng et al. }\end{array}$} & $73.0 \pm 4.6(\mathrm{C})$ & $48.8 \pm 3.4(\mathrm{C})$ & $1.49 \pm 0.05(\mathrm{C})$ \\
\hline & $68.8 \pm 4.6(\mathrm{~F})$ & $45.7 \pm 1.9(\mathrm{~F})$ & $1.51 \pm 0.06(\mathrm{~F})$ \\
\hline & $76.4 \pm 2.8(\mathrm{M})$ & $51.3 \pm 2.0(\mathrm{M})$ & $1.49 \pm 0.06(\mathrm{M})$ \\
\hline \multirow{3}{*}{$\begin{array}{c}\text { Japanese } \\
\text { Uehara et al. }{ }^{[2]}\end{array}$} & $74.3 \pm 6.6(\mathrm{C})$ & $48.3 \pm 5.4(\mathrm{C})$ & \\
\hline & $71.7 \pm 4.0(\mathrm{~F})$ & $46.6 \pm 3.6(\mathrm{~F})$ & \\
\hline & $83.0 \pm 6.2(\mathrm{M})$ & $53.8 \pm 6.6(\mathrm{M})$ & \\
\hline \multirow{3}{*}{$\begin{array}{c}\text { Koreans } \\
\text { Kwak et al. }{ }^{[16]}\end{array}$} & $71.9 \pm 5.6(\mathrm{C})$ & $45.7 \pm 3.8(\mathrm{C})$ & $1.57(\mathrm{C})$ \\
\hline & $67.6 \pm 3.1(\mathrm{~F})$ & $43.2 \pm 2.3(\mathrm{~F})$ & $1.56(\mathrm{~F})$ \\
\hline & $76.1 \pm 4.0(\mathrm{M})$ & $48.2 \pm 3.3(\mathrm{M})$ & $1.58(\mathrm{M})$ \\
\hline
\end{tabular}

(C- Combined males \& females, F- female, M- male)

\subsection{Comparison with conventional implants}

The Indian knees were compared to the following commercially available conventional implants - PFC Sigma Knee System (DePuy, USA), Freedom Knee System (MAXX, USA), NexGen LPS Flex Mobile Knee System (Zimmer Holdings, USA), Scorpio NRG Knee System (Stryker Corp., USA) and Buechel Pappas highflex mobile bearing knee system (TTK healthcare Ltd,. USA).

\subsubsection{Femoral Components}

In case of the femoral components, NexGen LPS and Scorpio NRG implants sizes had shown some correlation with the
Indian population (Figure 2). However, in other three systems implants with smaller fAP were undersized in fML and those with larger fAP showed overhang in fML i.e. the slope of the implant sizes and Indian population was different. This was clearly seen in the graph of femoral aspect ratio (fML/fAP) vs. fAP. The femoral aspect ratio of the Indian population showed a decreasing trend with increase in fAP; however, implants had an almost constant femoral aspect ratio (Figure 5).

For female population, the femoral components tended to be too large for a given AP measurement, with the most overhangs in the larger sizes (Figure 3). 


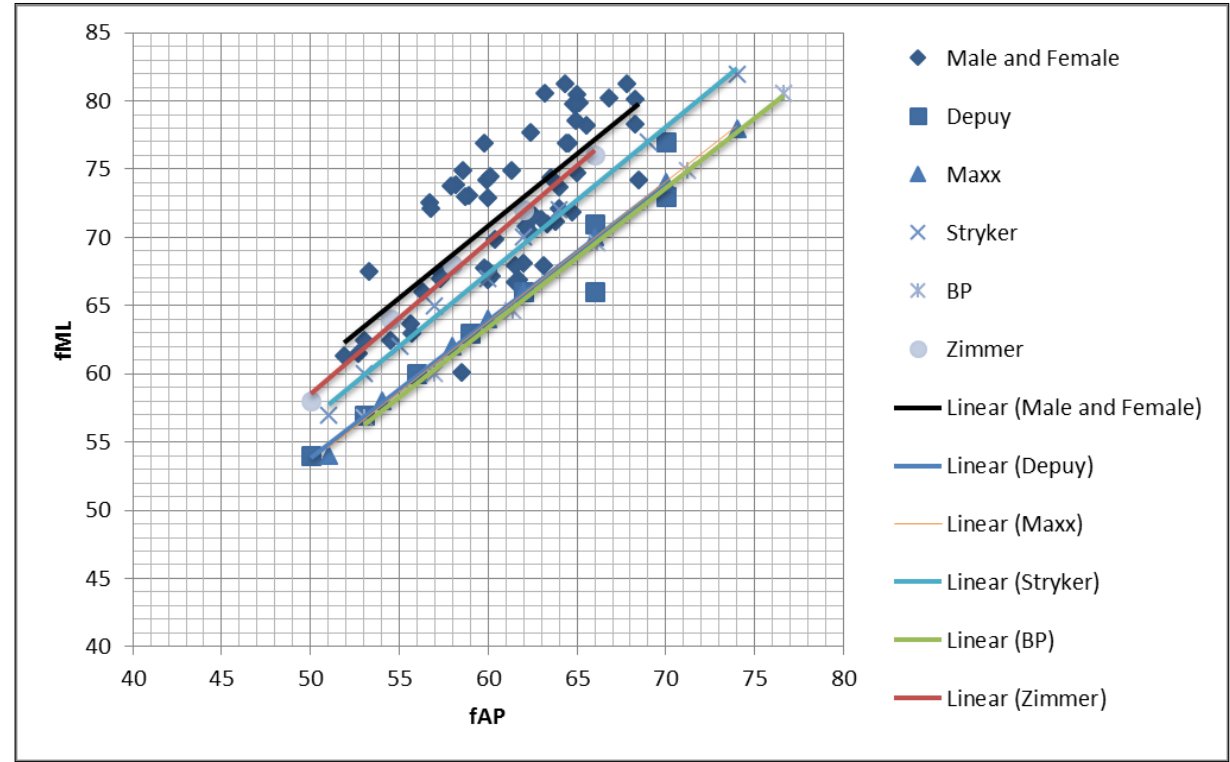

Fig 2: Comparison of fAP vs fML between study population and different knee systems.

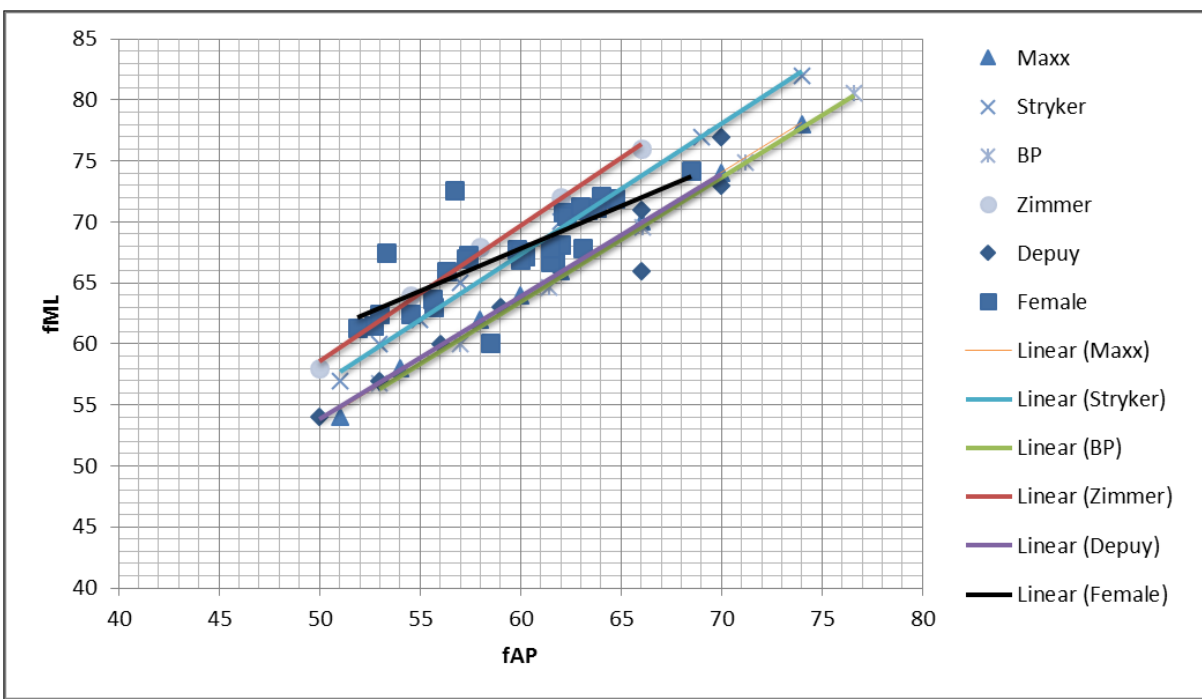

Fig 3: Comparison of fAP vs fML between female in study population and different knee systems.

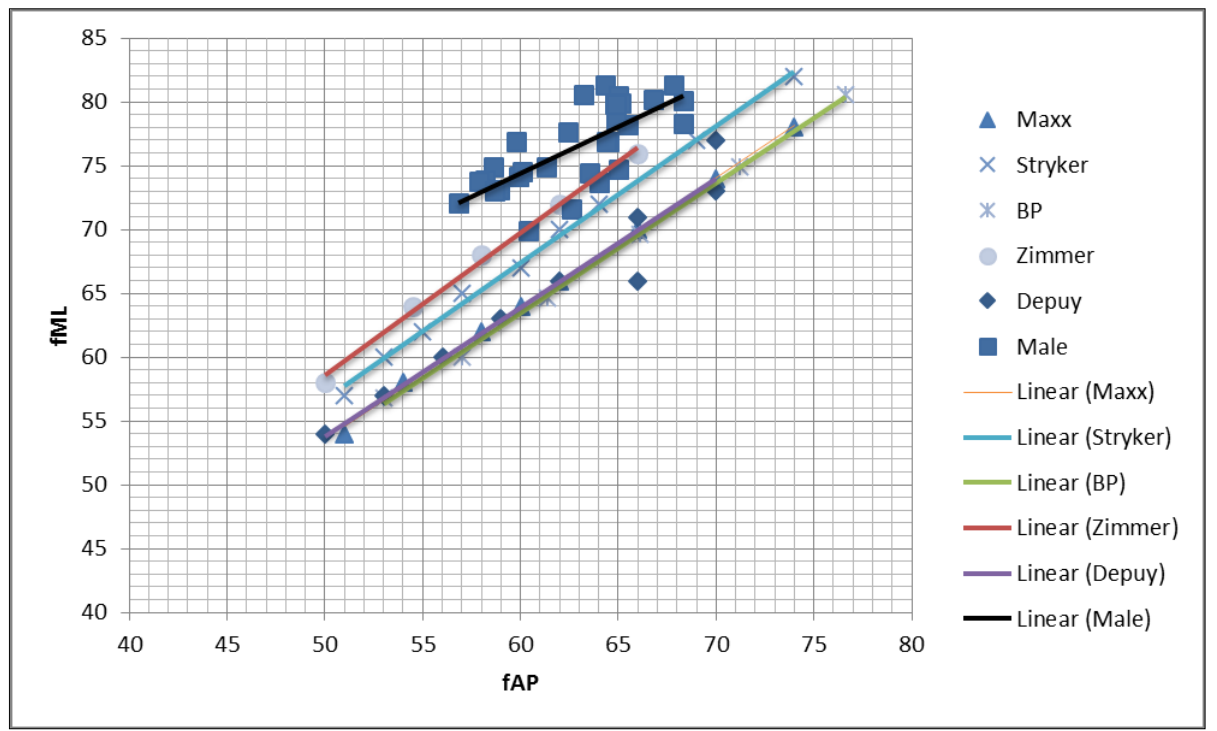

Fig 4: Comparison of fAP vs fML between male in study population and different knee systems. 


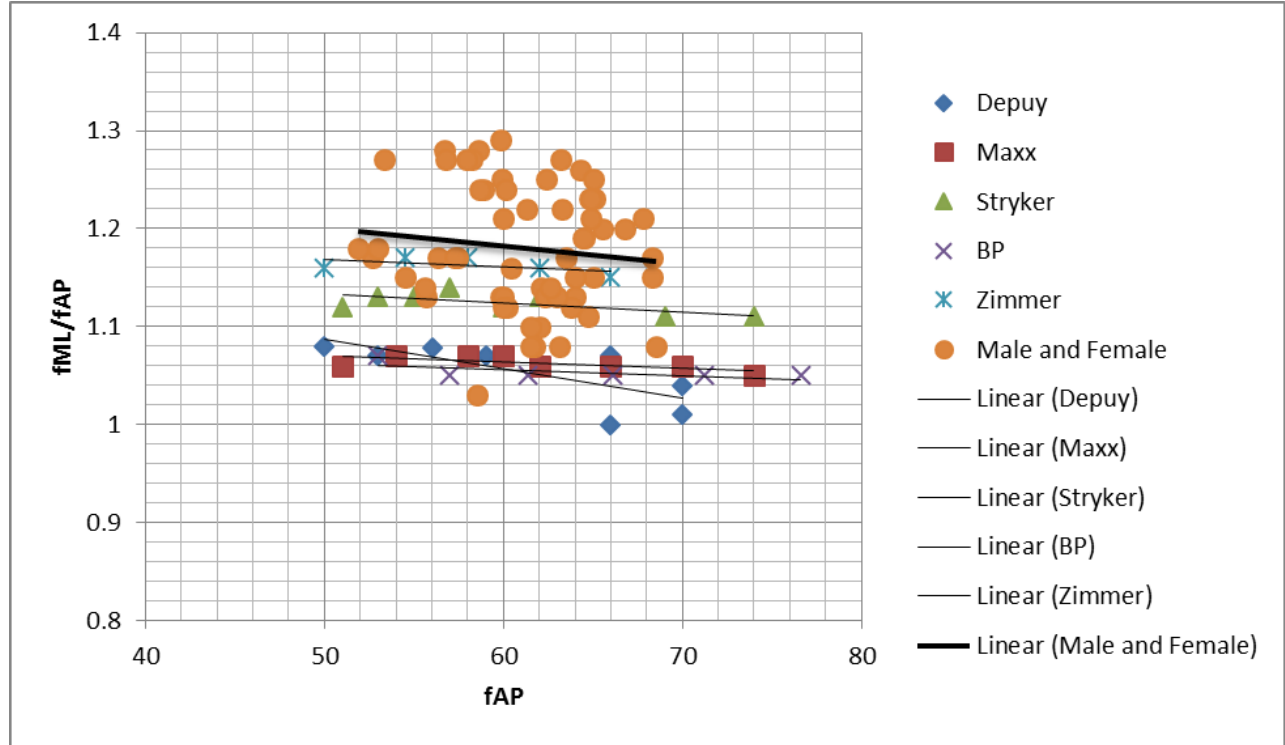

Fig 5: Comparison of fAP vs fML/fAP between study population and different knee systems.

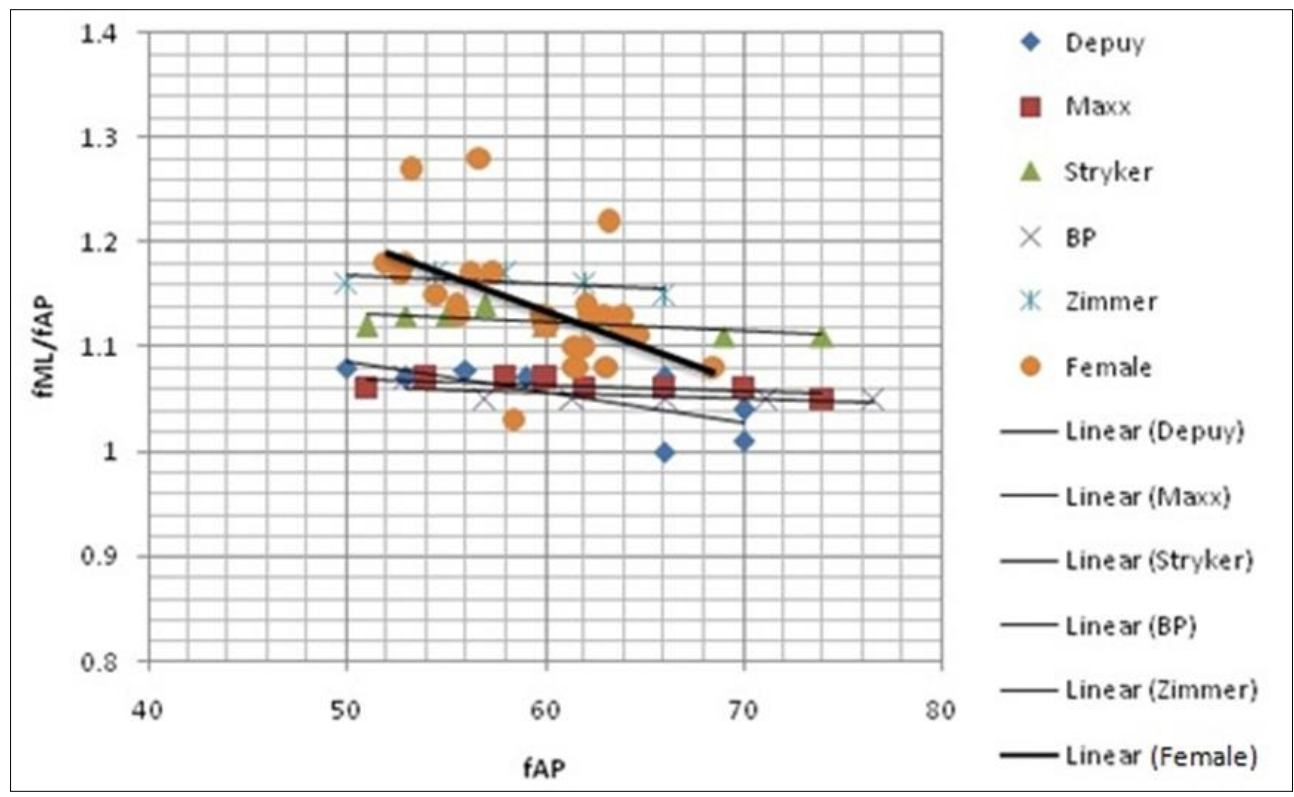

Fig 6: Comparison of fAP vs fML/fAP between female in study population and different knee systems.

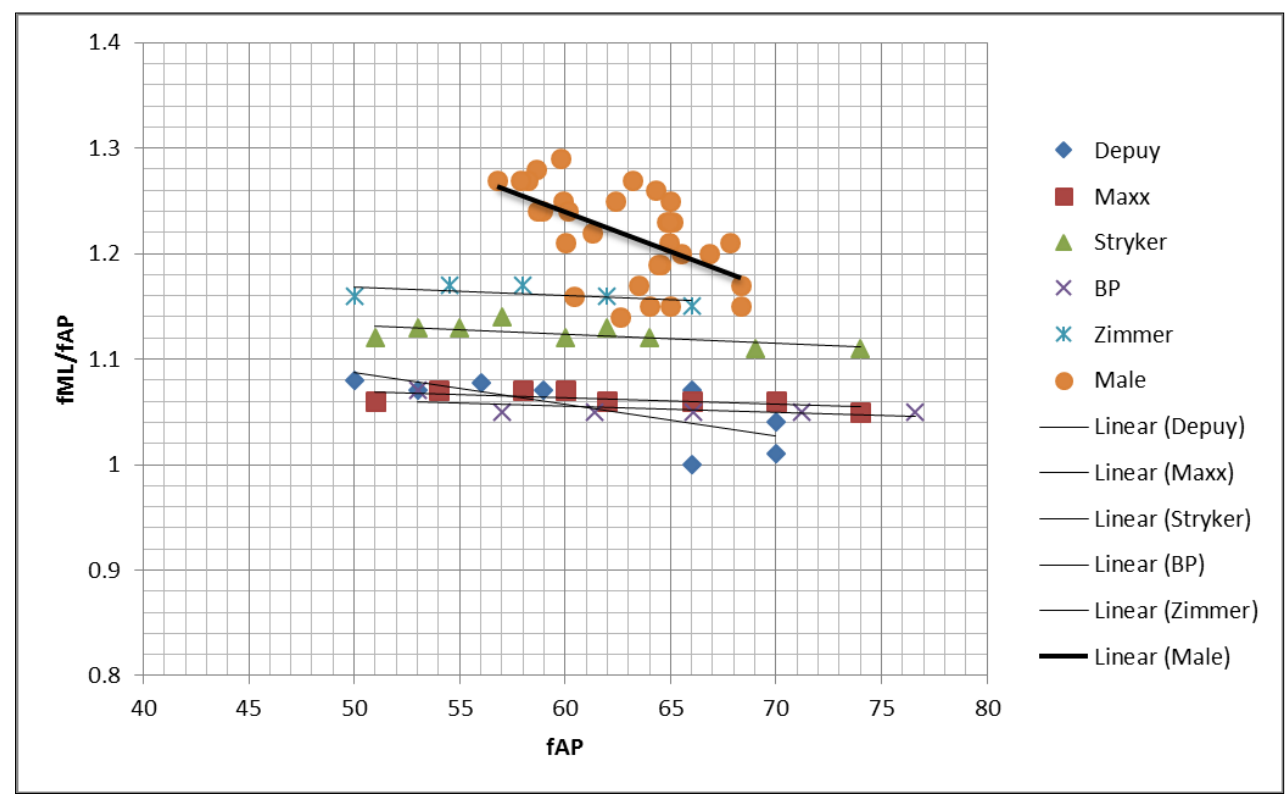

Fig 7: Comparison of fAP vs fML/fAP between male study population and different knee systems. 


\subsubsection{Tibial Components}

In case of the tibial components, the various implant sizes covered the entire range of the Indian population (Figure 8). However, as observed for femoral components, the slope of the implant sizes and Indian population was differentimplants with smaller tAP were undersized in tML and those with larger tAP showed overhang in tML (Figure 8). The graph of tibial aspect ratio (tML/tAP) vs. tAP clearly displayed the above result. Although the tibial aspect ratio of the Indian population had a decreasing trend with increasing tAP, implants had an almost constant tibial aspect ratio (Figure 11).

Like as the femoral components, for females tAP tended to be too large for a given tML measurement, with overhang in the larger sizes mainly in PFC DEPUY, Freedom MAXX and Scorpio NRG Stryker (Figure 9).

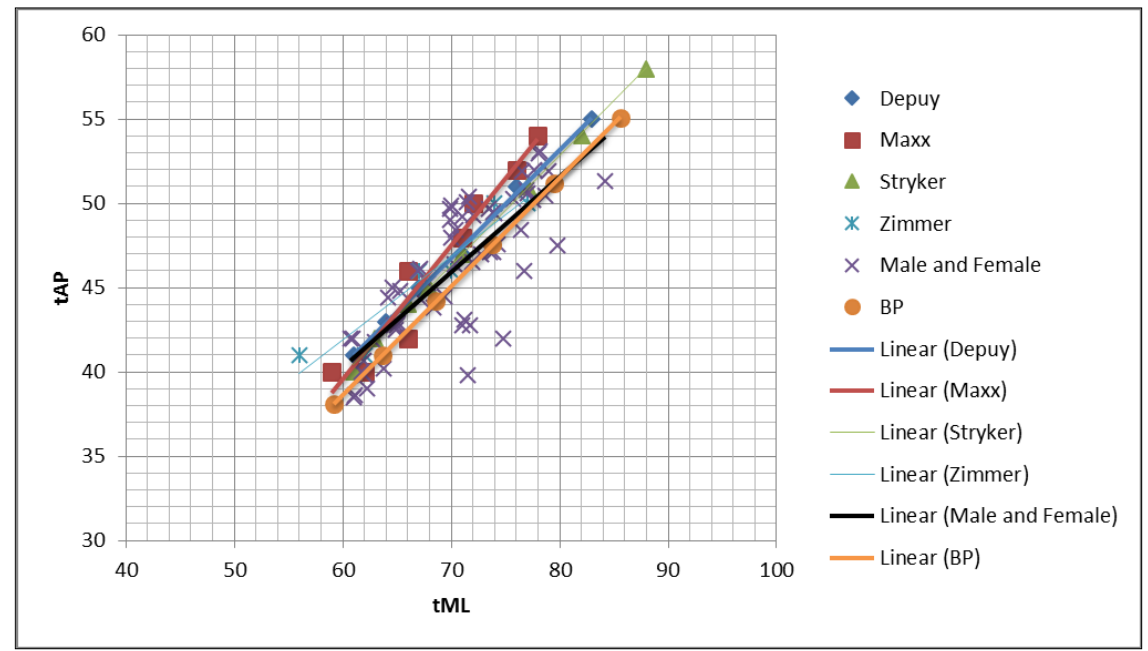

Fig 8: Comparison of tML vs tAP between study population and various knee systems.

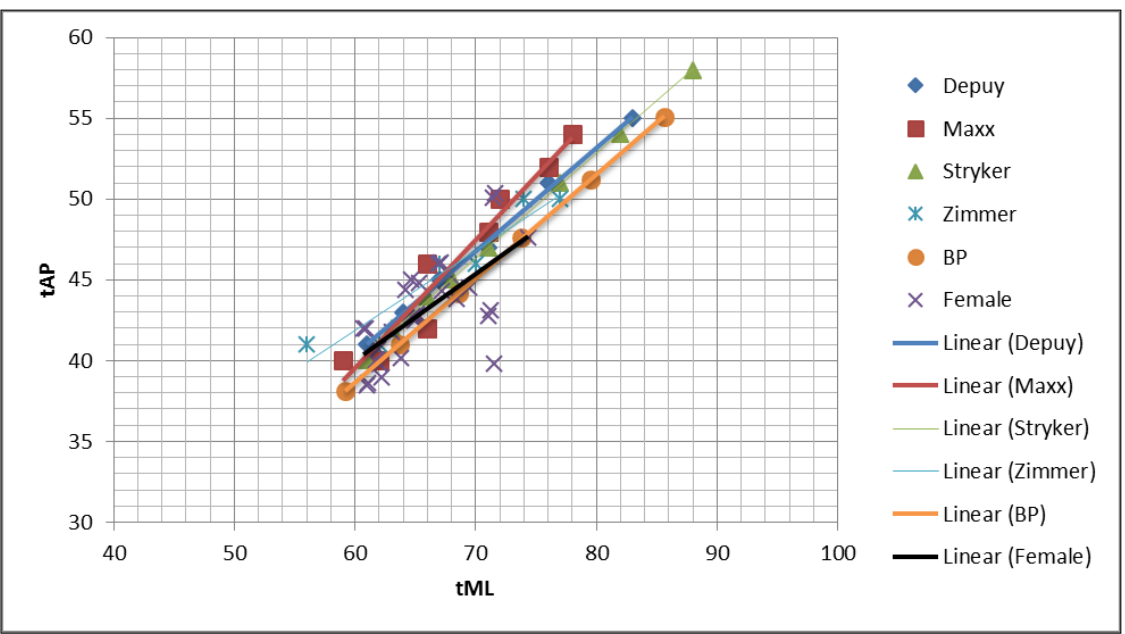

Fig 9: Comparison of tML vs tAP between female in study population and various knee systems.

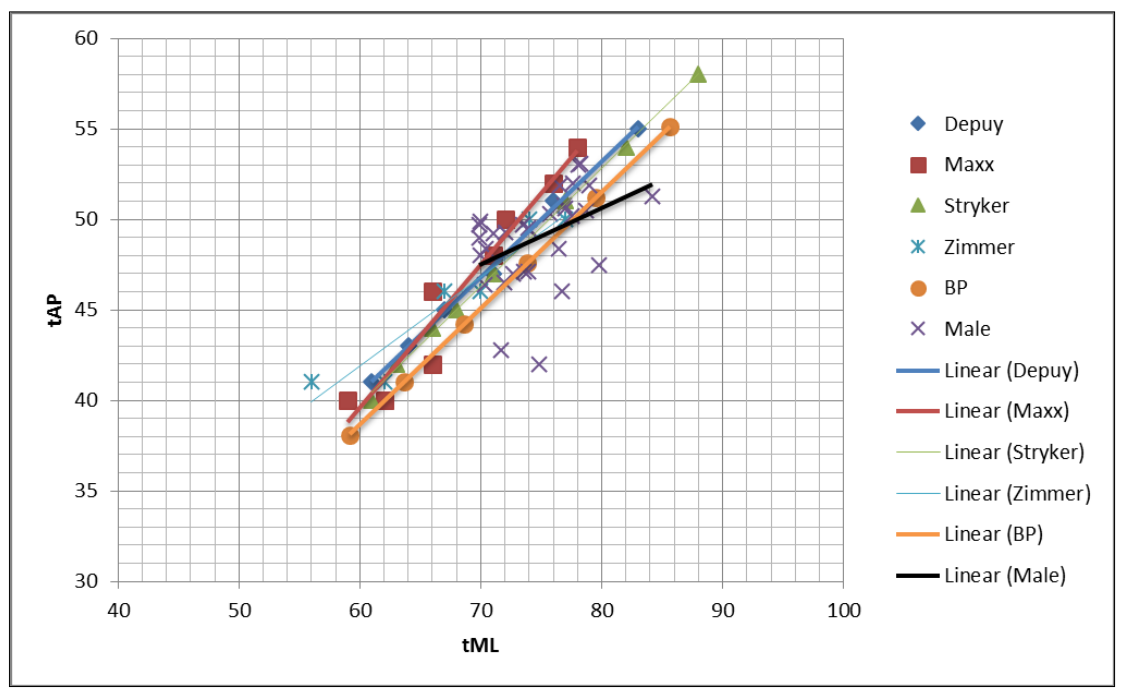

Fig 10: Comparison of tML vs tAP between male in study population and various knee systems. 


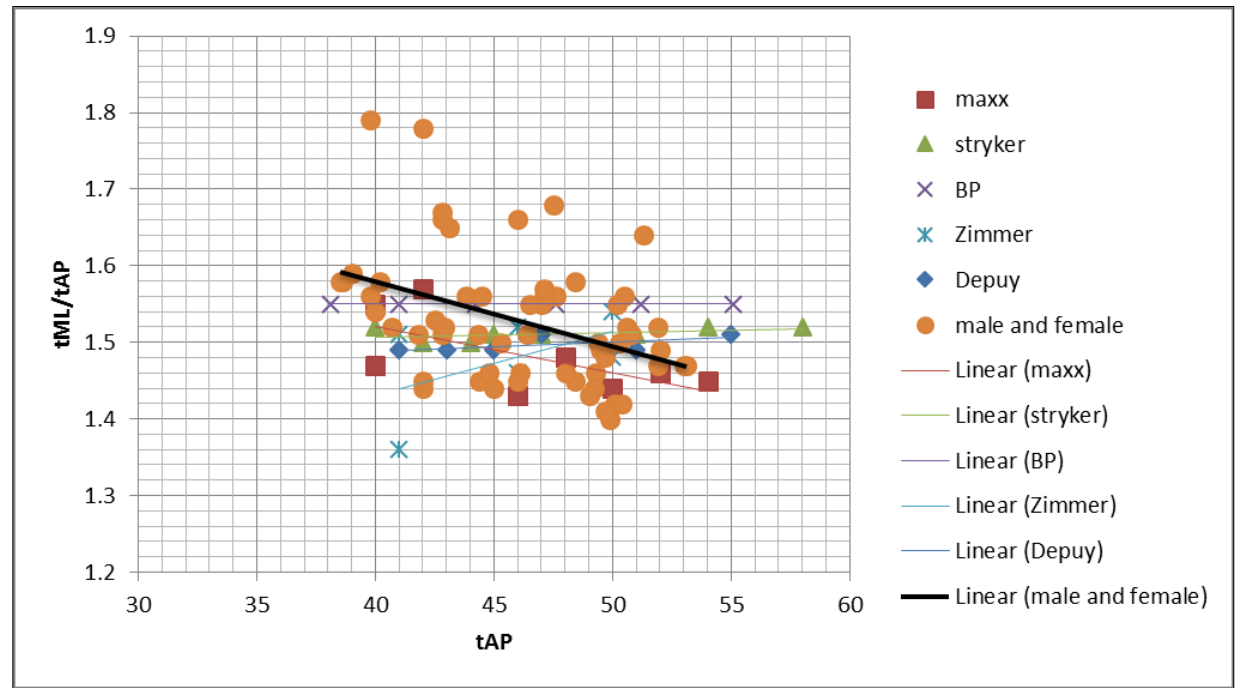

Fig 11: Comparison of tAP vs tML/tAP between study population and various knee systems

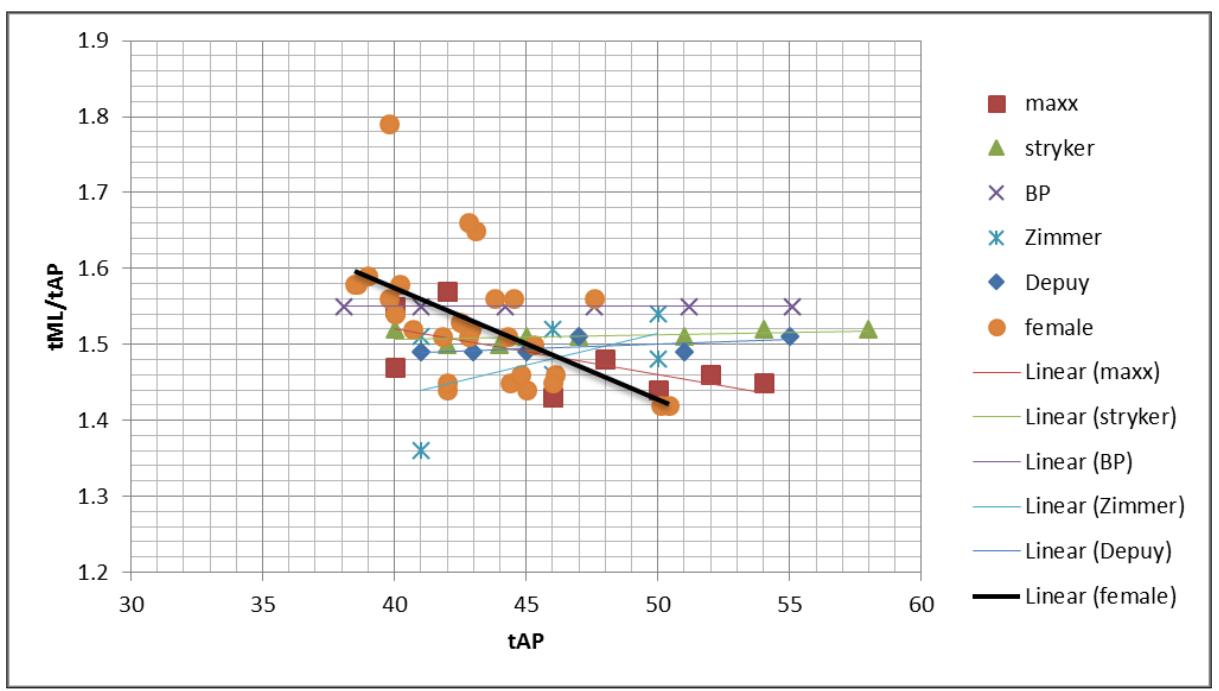

Fig 12: Comparison of tAP vs tML/tAP between female in study population and various knee systems

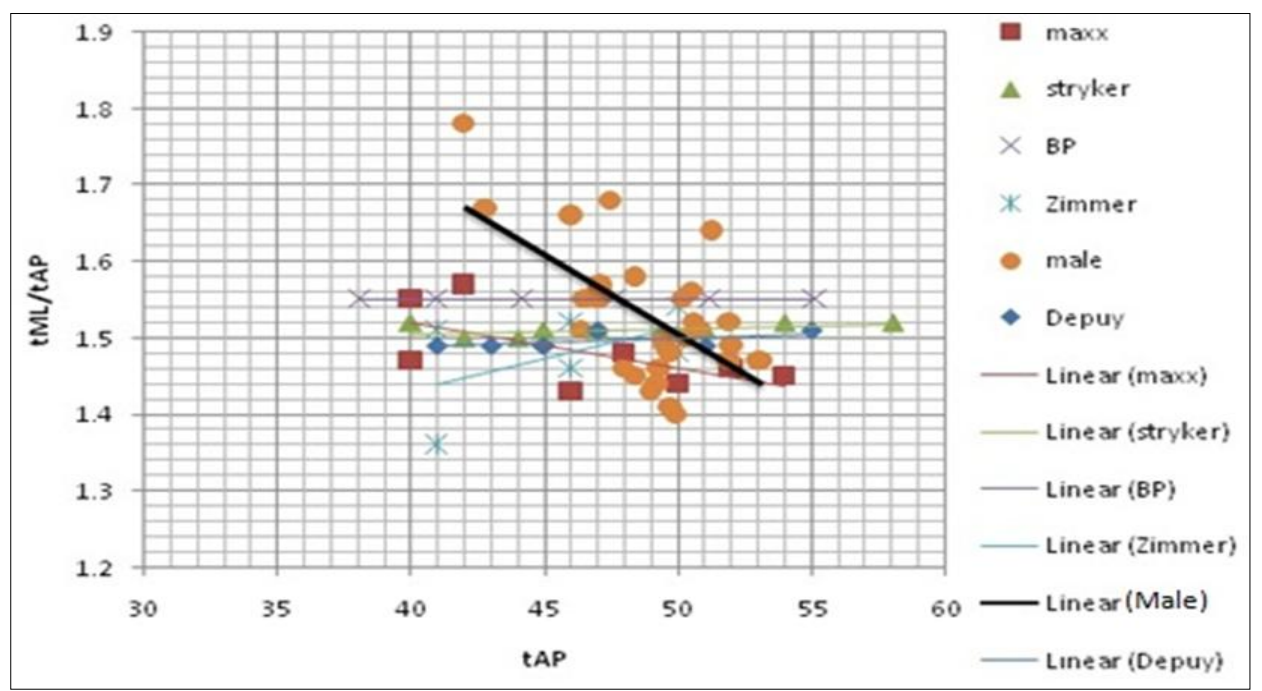

Fig 13: Comparison of tAP vs tML/tAP between male in study population and various knee systems

\section{Discussion}

For long term survival of total knee arthroplasty, replaced prosthesis should match the knee size of the patient ${ }^{[6]}$. Maximal implant coverage on the bone surface minimizes the stress applied to the bone-implant interface ${ }^{[4,5]}$. Most TKA prosthesis designs are based on the anthropometry of western population, which differs from Asian knee morphometry ${ }^{[3]}$.
Data of Indian knee morphometry of healthy and non osteoarthritic knee was lacking ${ }^{[10]}$.

We studied the knee morphometry of Indian healthy and non osteoarthritic knee. We found significant difference ( $\mathrm{p}<$ 0.001 ) in the measurement of fAP, fML, tAP, tML and femoral aspect ratio among males and females of study population (Table 2). 
We compared our data of Indian anthropometry with the data available in literature of other ethnic groups (Table 3). Indian fML was found to be smaller than that of Americans fML but larger than other ethnic group in study, while fAP of Indians was smallest (Table 3). tML and tAP of Indian knee was found to be least (Table 4).

This study used a 3D CT image technique for morphological measurements of the tibia and femur in an Indian population. The measurements from the $\mathrm{CT}$ images strongly correlate to intra-operative measurements since the 3D CT image of the knee can undergo unconstrained rotation and the correct three dimensional axis can be determined and maintained ${ }^{[17]}$.

The Indian knees were compared to Western implants which were commonly available in the Indian market and used by surgeons for TKA of Indian patients. In case of the femoral components, NexGen LPS and Scorpio NRG implants sizes had shown some correlation with the Indian population. However, in other three systems implants with smaller fAP were undersized in fML and those with larger fAP showed overhang in fML i.e. the slope of the implant sizes and Indian population was different (Figure 2). The femoral data of the Indian population showed a decreasing aspect ratio (fML/fAP) as the fAP dimension increased (Figure 5).

In case of the Indian tibia, the various implant sizes covered the entire range of the Indian population (Figure 8). However, as observed for femoral components, the slope of the implant sizes and Indian population was different, implants with smaller tAP were undersized in tML and those with larger tAP showed overhang in tML. The tibial aspect ratio (tML/tAP) of the Indian population decreased as the tAP increased (Figure 11).

In contrast to these observations in the aspect ratios of Indian patients, variations in aspect ratios of most implants were insignificant. For both the femur and tibia, it was found that the ML dimension was undersized with smaller AP and overhang was observed for larger AP dimensions. Thus our results suggest that Western implants may not be suitable for Indian patients.

The limitation of this study was that we measured the unresected sizes of 3D reconstructed knee, but our results were similar to other Indian study ${ }^{[10]}$. Also it was short term single institutional study, with smaller sample size.

\section{Conclusion}

Our study suggests that why Western implant mismatches when implanted in Indian patients. Also, this study provides definite rationale for designing total knee prosthesis, especially a gender-specific design suitable for the Indian population. This study clearly shows that while designing the prostheses, the relationship between aspect ratio and anteroposterior dimension of the tibia and femur should also be taken into account apart from the relationships between medio-lateral and antero-posterior dimensions.

\section{Acknowledgement}

No benefits or funds were received in support of this study. All authors report no conflict of interest.

\section{References}

1. Vaidya SV, Ranawat CS, Aroojis A, Laud NS. Anthropometric measurements to design total knee prostheses for the Indian population. J Arthroplasty. 2000; 15:79-85x.

2. Uehara K, Kadoya Y, Kobayashi A, Ohashi H, Yamano Y. Anthropometry of the Proximal Tibia to Design a
Total Knee Prosthesis for the Japanese Population. The Journal of Arthroplasty, 2002; 17:1028-1032.

3. Shah DS, Ghyar R, Ravi B, Shetty V. 3D morphological Study of the Indian Arthritic Knee: Comparison with Other Ethnic Groups and Conformity of Current TKA Implant. Open Journal of Rheumatology and Autoimmune Diseases. 2013; 3:263-269.

4. Insall JN. Surgical techniques and instrumentation in total knee arthroplasty. In: Insall JN, Windsor RE, Scott WN, editors. Surgery of the Knee. 2nd ed. New York: Churchill Livingstone. 1993, 739.

5. Incavo SJ, Ronchetti PJ, Howe JG, Tranowski JP. Tibia1 plateau coverage in total knee arthroplasty. Clin Orthop. 1994; 299:81-5.

6. Cheng CK, Lung CY, Lee YM, Huang CH. A new approach of designing the tibial base plate of total knee prosthese. Clin Biomech. 1999; 14:112-7.

7. Cheng FB, Ji XF, Lai Y et al. Three Dimensional Morphometry of the Knee to Design the Total Knee Arthroplasty for Chinese Population. Knee. 2009; 16:341-347

8. Urabe K, Miura H, Kuwano T, Matsuda S, Nagamine R, Sakai $\mathrm{S}$ et al. Comparison between the shape of resected femoral sections and femoral prostheses used in total knee arthroplasty in Japanese patients-simulation using three-dimensional computed tomography. J Knee Surg. 2003; 16:27-33.

9. Kim HA, Kim S, Seo YI et al. The Epidemiology of Total Knee Replacement in South Korea: National Registry Data. Rheumatology Oxford, 2008; 47:88.

10. Darshan Shah S, Rupesh Ghyar, Bhallamudi Ravi, Chintan Hegde, Vijay Shetty. Morphological Measurements of Knee Joints in Indian Population: Comparison to Current Knee Prostheses: Open Journal of Rheumatology and Autoimmune Diseases, 2014; 4:75-85.

11. Bing Yue, Kartik Varadarajan M, Songtao Ai, Tingting Tang, Harry Rubash E et al. Differences of Knee Anthropometry Between Chinese and White Men and Women. J Arthroplasty. 2011; 26(1):124-130. doi:10.1016/j.arth.2009.11.020.

12. Mohamed Mahfouz, Emam ElHak Abdel Fatah, Lyndsay Smith Bowers, Giles Scuderi. Three-dimensional Morphology of the Knee Reveals Ethnic Differences. Clin Orthop Relat Res. 2012; 470:172-185.

13. Berger RA, Rubash HE, Seel MJ, Thompson WH, Crossett LS. Determining Therotational Alignment of the Femoral Component in Total Knee Arthroplasty Using the Epicondylar Axis. Clinical Orthopaedics and Related Research, 1993; 286:40-47.

14. Griffin FM, Math K, Scuderi GR et al. Anatomy of the Epicondyles of the Distal Femur: MRI Analysis of Normal Knees. The Journal of Arthroplasty. 2000; 115:354-359.

15. Mensch J, Amstutz H. Knee Morphology as a Guide to Knee Replacement. Clinical Orthopaedics and D. S. Shah et al. 85 Related Research. 1975; 112:231-241.

16. Kwak DS, Sibin S, Patinharayil G et al. Morphometry of the Proximal Tibia to Design the Tibial Component of Total Knee Arthroplasty for the Korean Population. Knee, 2007; 14:295-300.

17. Lee IS, Choi JA, Kim TK, Han I, Lee JW, Kang HS. Reliability Analysis of 16-MDCT in Preoperative Evaluation of Total Knee Arthroplasty and Comparison with Intraoperative Measurements. American Journal of Roentgenolo gy, 2006; 186:1778-1782. 